\title{
Salvaging patients with extracorporeal life support resuscitation
}

\author{
Ming-Sing Si, MD \\ From the Department of Cardiac Surgery, Section of Pediatric Cardiovascular Surgery, University of Michigan, \\ Ann Arbor, Mich. \\ Disclosures: Author has nothing to disclose with regard to commercial support. \\ Received for publication June 22, 2016; accepted for publication June 22, 2016; available ahead of print July 25, \\ 2016. \\ Address for reprints: Ming-Sing Si, MD, 11-735 C.S. Mott Children's Hospital SPC 4204, 1540 E. Hospital Drive, \\ Ann Arbor, MI 48109-4204 (E-mail: mingsing@umich.edu). \\ J Thorac Cardiovasc Surg 2016;152:1140-1 \\ $0022-5223 / \$ 36.00$ \\ Copyright (c) 2016 by The American Association for Thoracic Surgery \\ http://dx.doi.org/10.1016/j.jtcvs.2016.06.047
}

Cardiac arrest in adult patients who are recovering from cardiac surgery carries a mortality rate of up to $83 \%{ }^{1}$ In this issue, Mazzeffi and colleagues ${ }^{2}$ from the University of Maryland present a retrospective single-center review of their experience using extracorporeal life support resuscitation (ECPR) to salvage this group of patients with refractory cardiac arrest. During the 6-year study period (2010-2015), 191 patients had a postoperative cardiac arrest. Twenty-three of these patients underwent ECPR for refractory cardiac arrest, and the causes for these arrests were diverse (cardiac tamponade, right ventricular failure, biventricular failure, coronary obstruction, respiratory arrest, and unknown). These investigators were available to perform cannulation and initiation of ECPR with a median time from start of arrest to full-flow support of 31 minutes. With this approach, they were able to salvage over $30 \%$ of these patients. Younger patients who underwent ECPR had an improved chance of survival. Further, most of the salvaged patients retained neurologic function. These authors concluded that ECPR may have a role in younger adult cardiac surgery patients with refractory cardiac arrest, and that additional studies are needed to identify patients who would benefit most from ECPR.

Although this is a retrospective study, the results demonstrate the benefits and premise of rapidly re-establishing effective systemic circulation in adult cardiac surgery patients with refractory cardiac arrest. However, these benefits are not across the board and, as the authors rightfully conclude, identifying those who would benefit from ECPR is important as it would decrease unnecessary use of this costly resource.

Intuitively, it would seem that attaining full-flow support on ECPR before irreversible cardiac and neurologic (as well as other organ system) injury has taken place is probably the most important factor determining clinical outcomes with this approach. However, in this study, length of conventional cardiopulmonary resuscitation (CCPR) before

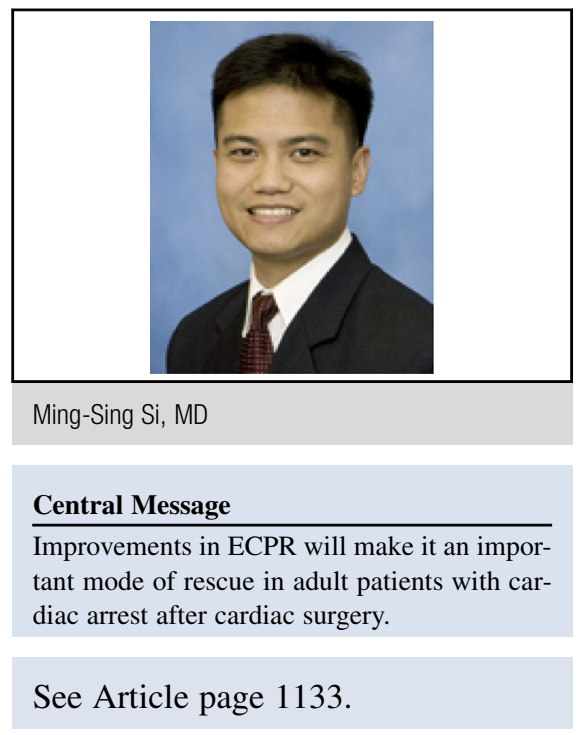

ECPR was not a significant factor in influencing outcomes. This seemingly counterintuitive result may be explained by the influence of several poorly characterized factors: magnitude of low cardiac output and vasopressor support before the arrest, intrinsic tissue/organ tolerance to ischemia, and the effectiveness of CCPR before full-flow extracorporeal life support (ECLS). Therefore, these unknowns confound any further analysis of the effects of CCPR time before full-flow ECLS on clinical outcomes. Experience with ECPR in pediatric patients with heart disease would also suggest this. In a study by Kane and colleagues, the length of CCPR was not found to be a predictor of outcome, but those with severe metabolic acidosis at the time of ECPR initiation had higher mortality. ${ }^{4}$

Thus, the primary goals of ECPR are expedient initiation and limiting the length of time of cardiac arrest, and suboptimal cardiac output and oxygen delivery from CCPR. This requires a rapid decision to pursue ECPR and activation of an advanced ECPR program with the appropriate personnel and infrastructure. ${ }^{5}$ Established institutional protocols for notification and deployment of the ECPR team are necessary. Immediate availability of surgeons who can perform central or peripheral cannulation is also requisite. Equally important is the on-site presence of nurses, specialists, or perfusionists who can rapidly prepare ECLS circuits.

With increasing recognition that ECPR and ECLS are beneficial in many types of dire clinical situations, ${ }^{6}$ 
widespread use is expected, which will further spur the development of more efficient infrastructure design, protocols, and techniques that will ultimately yield even more rapid initiation of ECPR. This may also increase the cost-effectiveness of ECPR. Finally, increased use of ECLS and ECPR will also help drive improvement of this technology that will favorably influence the risk-benefit ratio and may even decrease the cost of this therapy even further. For example, miniature circuits with smaller prime volumes and improved biocompatibility of the ECLS circuit components could decrease the inflammatory response and the need for blood component transfusions.

The study by Mazzeffi and colleagues ${ }^{2}$ could not have come at a better time. It not only highlights its use in adult cardiac surgery patients but also calls attention to its use in diverse clinical scenarios as well. It also points to the future where improvements in multiple areas will permit extremely rapid initiation of ECPR and salvage of even more patients with cardiac arrest. Certainly, much more work is needed to get to that point, and as professionals whose daily work involves the use of extracorporeal bypass, we should continue to spearhead research into this therapy and technology, which ultimately has a tremendous impact on many patients.

\section{References}

1. LaPar DJ, Ghanta RK, Kern JA, Crosby IK, Rich JB, Speir AM, et al. Hospital variation in mortality from cardiac arrest after cardiac surgery: an opportunity for improvement? Ann Thorac Surg. 2014;98:534-9; discussion 539-40.

2. Mazzeffi MA, Sanchez PG, Herr D, Krause E, Evans CF, Rector R. Outcomes of extracorporeal cardiopulmonary resuscitation for refractory cardiac arrest in adult cardiac surgery patients. J Thorac Cardiovasc Surg. 2016;152:1133-9.

3. Harvey MJ, Gaies MG, Prosser LA. U.S. and international in-hospital costs of extracorporeal membrane oxygenation: a systematic review. Appl Health Econ Health Policy. 2015;13:341-57.

4. Kane DA, Thiagarajan RR, Wypij D, Scheurer MA, Fynn-Thompson F, Emani S, et al. Rapid-response extracorporeal membrane oxygenation to support cardiopulmonary resuscitation in children with cardiac disease. Circulation 2010;122:S241-8

5. Swol J, Belohlavek J, Haft JW, Ichiba S, Lorusso R, Peek GJ. Conditions and procedures for in-hospital extracorporeal life support (ECLS) in cardiopulmonary resuscitation (CPR) of adult patients. Perfusion. 2016;31:182-8.

6. Gerke AK, Tang F, Cavanaugh JE, Doerschug KC, Polgreen PM. Increased trend in extracorporeal membrane oxygenation use by adults in the United States since 2007. BMC Res Notes. 2015;8:686. 